\title{
Relationship between functional castration and alpha- fetoprotein produced by hepatoma-bearing female rats
}

\author{
Thomas B. Pool, Nobuyoshi Hagino and Ivan L. Cameron \\ Department of Anatomy, The University of Texas Health Science Center at San Antonio, \\ 7703 Floyd Curl Drive, San Antonio, Texas 78284, U.S.A.
}

\begin{abstract}
Summary. In rats bearing Morris hepatoma No. 7777 , serum levels of alpha fetoprotein (AFP) increased as tumour size increased. Hepatoma-bearing females remained in dioestrus once the tumour exceeded a cross-sectional area of $12 \mathrm{~cm}^{2}$. The following changes were seen in tumour-bearing rats compared to control animals: uterine wet weight was significantly decreased, the uterine epithelial mucosa was lower, castration cells developed in the anterior pituitary, and there was a 3- to 23-fold elevation in serum oestrogen levels. We conclude that circulating oestrogen is bound to AFP in hepatoma-bearing female rats and that in this bound state it is unable to exert its normal physiological actions.
\end{abstract}

\section{Introduction}

Alpha-fetoprotein (AFP) is a serum glycoprotein that normally appears in fetal and maternal serum at parturition. The concentrations of fetal and maternal serum AFP are high towards the end of gestation in the rat but drop sharply after birth to very low levels (Sell, 1973, 1974; Sell \& Alexander, 1974; Sell, Becker, Leffert \& Watabe, 1976). AFP is synthesized predominately by the fetal liver and yolk sac during development (Gitlin, 1975) but is also produced in adults with hepatomas (Abelev, 1968; Sell, 1974), teratoblastomas (Abelev, 1968; Sell \& Alexander, 1974), liver trauma (StanislawskiBirencwajg, Uriel \& Grabar, 1967), non-malignant liver diseases (Ruoslahti, Pihko \& Seppala, 1974), and chemically-induced carcinomas (Watabe, 1971). High levels of AFP in adult sera are most often associated with primary cancer of the liver and can be of diagnostic value (Abelev, 1968, 1971, 1974; Ruoslahti et al., 1974). The appearance of AFP in development and oncogenesis, its sites of synthesis, physical characteristics and immunological properties, have been extensively studied and reviewed (Abelev, 1968, 1971, 1974; Adinolf, Adinolfi \& Lessof, 1975; Ruoslahti \& Pihko, 1975; Sell et al., 1976). However, the physiological effects of high levels of serum AFP in adults, such as can occur with primary liver cancer, have not been studied. The present investigation was therefore undertaken to determine the effects of AFP upon the reproductive biology of female rats with hepatoma.

\section{Materials and Methods}

Oestrous cycle and microscopy. A total of 16 female Buffalo rats aged 7 weeks and of uniform body weight (approx. $180 \mathrm{~g}$ ) were randomly allocated to one of two groups. The animals were housed individually and a pelleted diet and water were always available. Rats from one group (A) were inoculated subcutaneously in the right flank with a $0.25 \mathrm{ml}$ suspension of Morris hepatoma No. 7777 cells (Cameron \& Pavlat, 1976). The control rats in Group B were untreated. Body weights were recorded daily for both groups. The length and width of the tumour were measured and the crosssectional area of the tumour was calculated with the formula for an ellipse. At the end of the experiment, the weight of each tumour was determined and its proportion of the body weight calculated (tumour wt/body wt - tumour wt). 
After tumour inoculation, vaginal smears were prepared daily for the first 3 weeks of the experiment from all animals and the stage of the oestrous cycle was assessed by examination of the smears with phase-contrast microscopy. The rats in both groups were killed by decapitation at 14 weeks of age. Ovaries and uteri were excised and weighed before fixation in paraformaldehyde (Winborn \& Seelig, 1970). Paraffin-wax sections $(7 \mu \mathrm{m})$ were stained with Harris' haematoxylin and eosin or with periodic acid-Schiff reagent. Anterior lobes of pituitary glands were rapidly removed and fixed in equal parts of ice-cold osmium tetroxide $(2 \%)$ and paraformaldehyde $(4 \%)$ in $0 \cdot 1 \mathrm{M}$-cacodylate buffer ( $\mathrm{pH} 7.0$ ) as described by Shiino, Williams \& Rennels (1972). The tissues were dehydrated in graded acetones and embedded in Spurr's low viscosity medium. Thin sections (silver to gold interference colours) cut with a diamond knife were mounted on copper grids, stained with uranyl acetate (Watson, 1958) and lead citrate (Venable \& Coggeshall, 1965) and examined in a Siemens 1A electron microscope.

Oestrogen analysis. Individual blood samples, collected immediately after decapitation, were allowed to coagulate at room temperature for $30 \mathrm{~min}$. Following centrifugation $(2000 \mathrm{~g})$, serum samples were aspirated into separate tubes for storage at $4^{\circ} \mathrm{C}$. Oestrogen concentrations were determined by the radioimmunoassay described by Abraham, Hopper, Tulchinsky, Swerdloff \& Odell (1971) using $\left[6,7-{ }^{3} \mathrm{H}\right]$ oestradiol-17 $(\mathrm{sp}$. act. $44 \mathrm{Ci} / \mathrm{mmol}$ : Amersham/Searle). The standard curve was prepared with oestradiol-17 $\beta$ (Sigma). The antibody (S-52 No. 5) to oestradiol-17 $\beta$ was obtained from the Professional Staff Association at Harbor General Hospital, Torrance, California. The crossreactions of this antibody have been tested against 16 steroid hormones (Abraham et al., 1971). The percentage cross-reactivity is less than 0.01 for all steroids tested except oestrogens. The crossreactivity was $100 \%$ with oestradiol- $17 \beta, 40 \%$ with oestradiol- $17 \alpha$ and $35 \%$ with oestrone; the procedure is therefore referred to as an oestrogen assay although the antibody was prepared against oestradiol-17 $\beta$. The coefficient of within-assay variation was $3 \cdot 34 \%$ in the range of $10-100 \mathrm{pg} / \mathrm{ml}$ and the sensitivity of the assay was $50 \mathrm{pg} / \mathrm{ml}$. All samples were assessed in duplicate.

Serum proteins. Blood was collected as described above from a third group (C) of 13 female rats bearing hepatomas of various sizes and from control animals (Group B). Serum samples were prepared and analysed by polyacrylamide gel electrophoresis (Davis, 1964) with $5.5 \%$ gels and a Trisglycine/Tris- $\mathrm{HCl}$ discontinuous $\mathrm{pH}$ system. Serum samples, diluted 1:25 with $10 \%$ glycerol and bromphenol blue, were applied to gels (100 $\mu \mathrm{l}$, equivalent to I $\mu \mathrm{l}$ serum) and electrophoresed at $4 \mathrm{~mA} /$ tube. Rat amniotic fluid collected from a normal fetus at Day 20 of gestation was also diluted with glycerol-tracer dye at the above concentration and electrophoresed as a marker for AFP (Lai, Forrester, Hancock, Hay \& Lorscheider, 1976). Other standards included bovine serum albumin (fraction V), transferrin, and rat IgG (Miles Research Products). The gels were stained with Coomassie blue, destained in methanol-acetic acid, and scanned in a Gilford model 2400 spectrophotometer at a wavelength of $550 \mathrm{~nm}$. Peak areas on the densitometric tracings were determined by means of a digital planimeter with a metrographic terminal. The staining reaction is stoichiometric within the range of serum protein concentrations used and is reflected in increases in peak areas that are commensurate with increases in total protein applied to gels. Peak areas were converted to a percentage of the total staining area above background. This allowed values for peak areas to be subjected to statistical analysis (Student's $t$ test).

\section{Results}

Identification of AFP. Two deeply staining post-albumin bands were seen in the serum samples from the tumour-bearing females but not those from control females (Text-figs la and b). These bands were also present in amniotic fluid collected from a normal rat fetus on Day 20 of gestation (Text-fig. 1c). The post-albumin bands in the hepatoma-bearing rats were identified as AFP because it is known that (1) Morris hepatoma No. 7777 produces AFP, (2) the bands are not present in normal rat serum, and (3) these proteins co-migrate with two amniotic fluid proteins which have been identified as slow and fast AFP (Lai et al., 1976). 


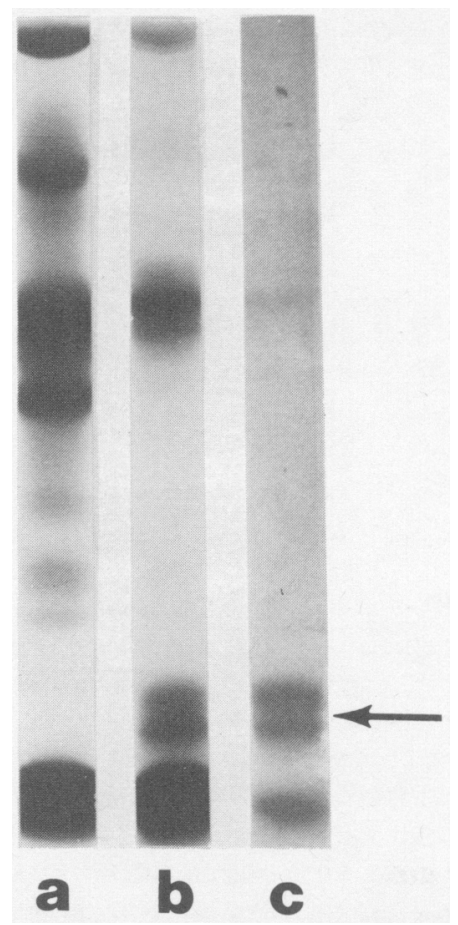

Text-fig. 1. Electrophoretic patterns of proteins from (a) normal rat serum, (b) rat serum from female bearing Morris hepatoma No. 7777, and (c) amniotic fluid from a rat fetus at Day 20 of gestation. Slow and fast forms of AFP in the amniotic fluid (arrow) can be compared with similar bands in (b). In all cases the origin is at the top and albumin is at the bottom.

Tumour size and serum AFP levels. As shown in Text-fig. 2, peak areas for serum albumin decrease in hepatoma-bearing rats as tumour size increases; while peak areas for slow and fast AFP increase linearly and uniformly with hepatoma growth. The slope values for regression lines of both slow and fast AFP were tested against a theoretical slope of zero using Student's $t$ test and both differed significantly $(P<0.001)$ from a slope of zero. The slow and fast AFP combined accounted for as much as $15 \%$ of the total absorbance from polyacrylamide gels of serum samples from females bearing large tumours.

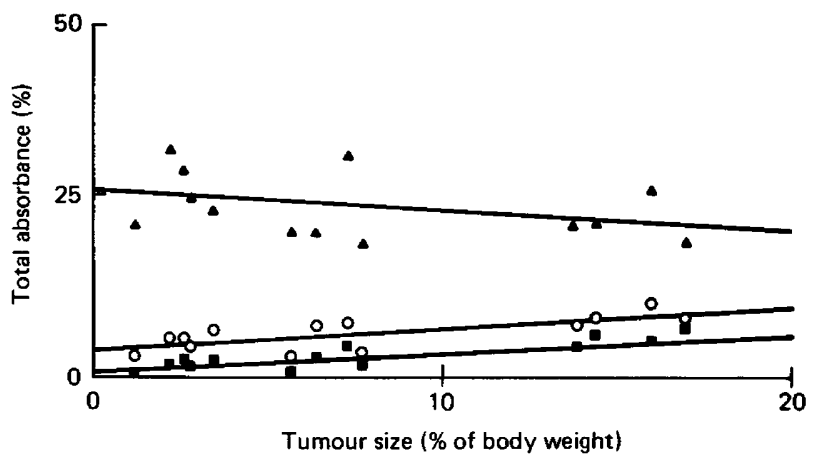

Text-fig. 2. Changes in peak areas of albumin ( $\Delta$ ), slow AFP ( $\boldsymbol{(})$, and fast AFP (O) from polyacrylamide gels of serum from rats with tumours of different sizes (expressed as a \% of body weight). The slope values $(-0.27$ for albumin, 0.30 for fast AFP and 0.31 for slow AFP) are all significantly different $(P<0.05)$ from a slope of zero as determined by Student's $t$ test. 
Table 1. Comparisons of data (mean \pm s.e.m., no. of animals in parentheses) from control and hepatoma-bearing female rats

\begin{tabular}{lccc}
\hline & Control (6) & Experimental (4) & Significance \\
\hline $\begin{array}{c}\text { Body weight (g) } \\
\text { Ovarian weight (g) } \\
\text { as \% of body wt }\end{array}$ & $241 \pm 2.8$ & $190 \pm 15.9$ & $P<0.02$ \\
$\begin{array}{c}\text { Uterine weight (g) } \\
\text { as \% of body wt }\end{array}$ & $0.18 \pm 0.007$ & $0.07 \pm 0.01$ & N.S. \\
$\begin{array}{c}\text { Uterine epithelial } \\
\text { cell height }(\mu \mathrm{m})\end{array}$ & $23.05 \pm 0.89$ & $14.58 \pm 0.59$ & $P<0.01$ \\
\end{tabular}

Ovarian and uterine weights and histology. The mean body weights of rats in Groups A and B differed by the end of the experiment (Table 1). Ovarian wet weights expressed as a percentage of body weight did not differ, but there were marked changes in ovarian histology in the tumour-bearing animals (Pl. 1, Figs 1 and 2; Pl. 2, Figs 3 and 4). In the ovaries from the Group A rats the luteal cells appeared to be surrounded by enlarged sinusoidal-like capillaries, and the interstitial cells were more vacuolated than those in Group B animals. The uterine epithelium of the control rats was columnar and vacuolated (P1. 2, Fig. 5), but in the experimental animals the cells became less vacuolated and more cuboidal as the tumour grew (Pl. 2, Figs 6-8). The depth of stroma and myometrium of the hepatoma-bearing rats was also less than in normal females. These differences in histology can be correlated with the lower uterine weights of the Group A rats.

Oestrous cycle changes. During the first 3 weeks of the experiment all control females exhibited normal oestrous cycles but those with tumours remained in dioestrus once the cross-sectional area of the tumour had reached approximately $12 \mathrm{~cm}^{2}$ (i.e. $30 \pm 1.26$ days after inoculation). Vaginal smears were taken from both groups for an additional 5 days before autopsy; the cell patterns of all 8 experimental animals were still typical of dioestrus.

Pituitary cytology. Enlarged basophilic cells with eccentric nuclei were seen in pituitaries from hepatoma-bearing females (Pl. 3, Fig. 9). The large centralized Golgi complex was seen as a clear halo in light micrographs (PI. 3, Fig. 9). Ultrastructural observations also suggested that these cells were gonadotrophs (Pl. 3, Figs 10 and 11 ). Secretory granules (mean diam. $150 \mathrm{~nm}$ ) were present in these cells and in similar, but not enlarged, cells in pituitaries of control females.

Table 2. Oestrogen concentrations in serum from normal and hepatoma-bearing female rats

\begin{tabular}{cccr}
\hline Group & $\begin{array}{c}\text { Tumour size }(\mathrm{g}) \\
\text { as \% body wt }\end{array}$ & $\begin{array}{c}\text { Oestrogen } \\
(\mathrm{pg} / \mathrm{ml})\end{array}$ & $\begin{array}{c}\text { Increase over mean } \\
\text { control value }\end{array}$ \\
\hline A. Experimental & 5 & 284.64 & \\
1 & 14 & $2364 \cdot 30^{*}$ & 2.80 \\
2 & 30 & 418.63 & 23.03 \\
3 & 32 & $441 \cdot 38$ & 4.08 \\
4 & & 102.66 & $4 \cdot 30$ \\
B. Control & & \pm 5.12 & \\
$( \pm$ s.e.m.) & & & \\
\hline
\end{tabular}

* Value extrapolated from the nonlinear portion of the standard curve. 


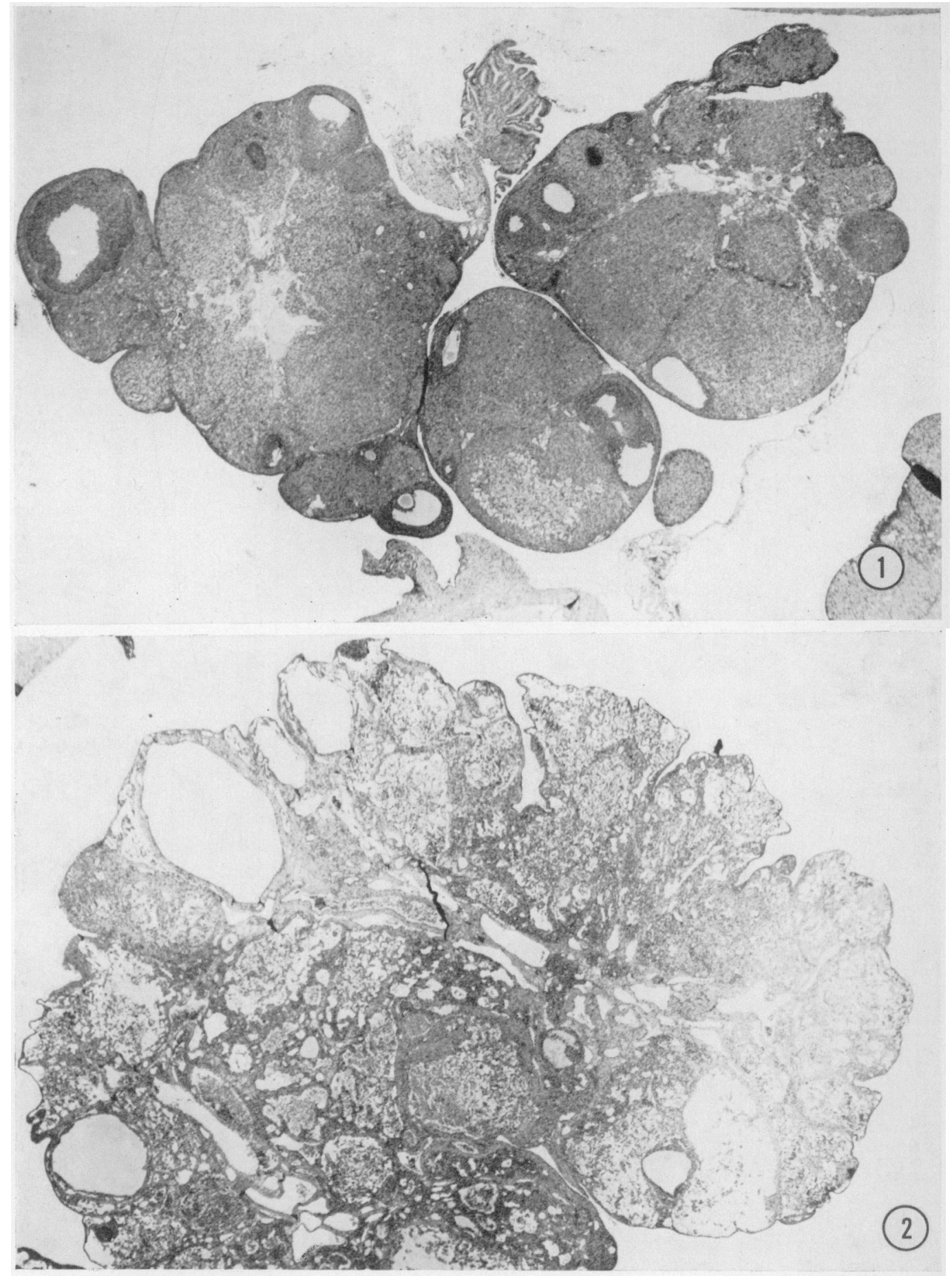

Fig. 1. Ovary from one of the control rats showing the presence of maturing follicles and corpora lutea of different generations. $\mathrm{H} \& \mathrm{E}, \times 85$.

Fig. 2. Ovary from a rat bearing a hepatoma. The lack of corpora lutea and follicles indicates the abnormal reproductive state of the animal. $H \& E, \times 85$. 


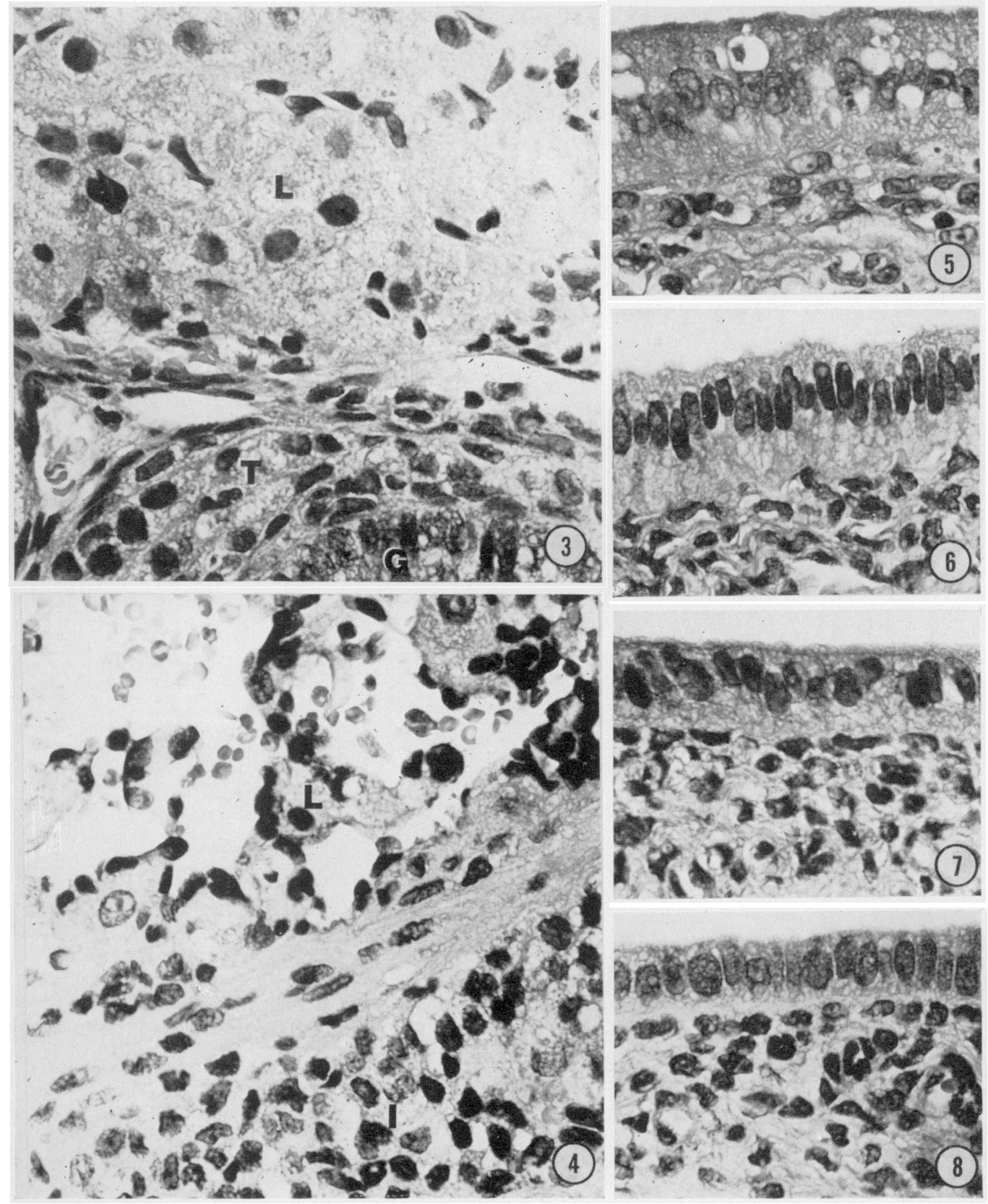

Fig. 3. Luteal (L), theca interna (T) and granulosa $(G)$ cells in the ovary of a control rat. $H \& E, \times 2700$.

Fig. 4. Luteal cells (L) surrounded by sinusoidal-like capillaries in the ovary of a tumour-bearing rat. Note the vacuolated appearance of the interstitial cells (I). H \& E, $\times 2700$.

Fig. 5. Uterine epithelial cells from control female. Note the columnar morphology and vacuolated appearance. $\mathrm{H} \& \mathrm{E}, \times 2700$.

Figs 6-8. Uterine epithelial cells from rats bearing a small- (Fig. 6), medium- (Fig. 7) and large (Fig. 8) sized hepatoma. $\mathrm{H} \& \mathrm{E}, \times 2700$. 

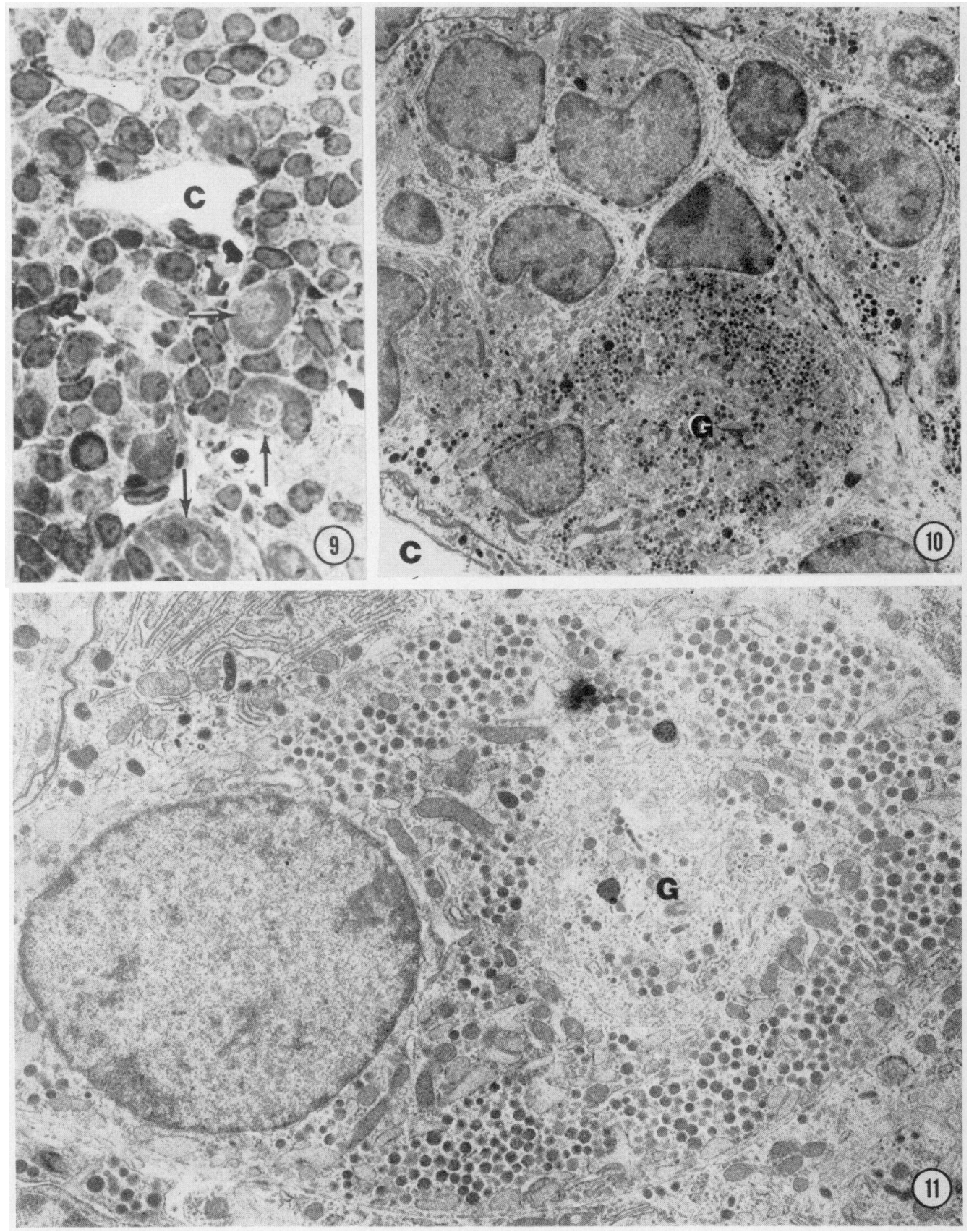

Fig 9. Section from anterior pituitary of a tumour-bearing rat. Enlarged gonadotrophs (arrows) show a central halo representing the Golgi complex. C, capillary. Azure II-methylene blue, $\times 3650$.

Fig. 10. Electron micrograph of the anterior pituitary of a tumour-bearing rat showing the enlarged gonadotroph (G). $\times 6550$.

Fig. 11. Electron micrograph of gonadotroph from hepatoma-bearing rat showing the eccentric nucleus, centralized Golgi region $(G)$, and numerous secretory granules. $\times 15200$. 
Oestrogen levels. As shown in Table 2, oestrogen levels in the tumour-bearing rats were significantly $(P<0.001)$ higher than those in control animals and could be related to tumour size.

\section{Discussion}

The Morris hepatoma No. 7777 is a rapidly growing tumour that produces high levels of serum AFP (Sell et al., 1972, 1974a, 1976; Sell \& Morris, 1974; Lai et al., 1976) which increase exponentially in Buffalo rats with time after tumour inoculation (Sell et al., 1974b). The present study shows that the increases in slow and fast AFP are a linear function of hepatoma size. Although our technique lacks the sensitivity of radioimmunoassay, it is an inexpensive procedure that permits simultaneous comparison of the relative amounts of host serum proteins and AFP in experiments in which extreme sensitivity is not required. For example, the pattern of decline in serum albumin in the present experiment indicates the rate of cancer cachexia in hepatoma-bearing rats. It is therefore possible to correlate qualitative and quantitative changes in serum AFP with the general health of the experimental animal.

Rat AFP is known to have oestrogen-binding activity (Uriel, de Nechaud \& Dupiers, 1972; Aussel, Uriel \& Mercier-Bodard, 1973; Uriel, Aussel, Bouillon, de Nechaud \& Loisillier, 1973; Uriel, Aussel, Bouillon, Louissilier \& de Nechaud, 1975); the association constant for AFP and oestradiol is $6 \times 10^{7} \mathrm{M}^{-1}$ whereas that for AFP and oestrone is $1 \times 10^{8} \mathrm{M}^{-1}$ (Aussel et al., 1973). Additionally, there appears to be one molecule of oestrogen bound per molecule of AFP (Aussel et al., 1973; Uriel et al., 1975). Rat AFP therefore appears to possess high affinity and low capacity, as do other specific steroid receptor proteins. It is these properties of rat AFP to which we attribute the changes in reproductive physiology in the hepatoma-bearing rats. The cessation of oestrus in hepatoma-bearing rats is correlated with a specific threshold in tumour size. The morphology of the ovarian luteal cells in the tumour-bearing rats is that of a cell active in steroid production (oestrogens), but the uterine morphology of these animals more closely resembles that of a rat with low circulating oestrogen levels, and the anterior pituitary cells resemble the hypertrophied gonadotrophs typical of castrated rats (Szentágothai, Flerko, Mess \& Halasz, 1962).

It is conceivable that the differences seen in the experimental group were due to the onset of cancer cachexia. This possibility was not excluded experimentally, but the data show that the response is specific. We find it difficult to at tribute the significant increases in circulating oestrogens in the experimental animals to a generalized decline in the nutritional status of the tumour-bearing animals. Additionally, ovarian weights did not differ significantly between Groups A and B. We therefore conclude that the females with hepatomas are producing high levels of oestrogens (Table 2), but that these steroids are being rapidly bound to the AFP produced by the hepatoma. The antibody employed for the radioimmunoassay apparently has a much higher affinity for oestrogens than does AFP and thus permits accurate values of circulating oestrogen levels to be obtained although the bound and free forms of hormone cannot be distinguished.

It is not certain whether or not a similar interaction between high AFP levels and oestrogens can occur in man with primary cancer of the liver. There are conflicting reports in the literature regarding the capacity of human AFP to bind oestrogens (Uriel et al., 1975) but the methods used may not have been sensitive enough. It has also been suggested that AFP may exist in different conformational states, only one of which may be able to bind oestrogens (Uriel et al., 1975). If oestrogens, when complexed with AFP, are unable to exert normal physiological actions upon target organs, including the hypothalamus, as found in the present experiments with rats, then measurements of total serum oestrogen levels become less meaningful and it seems important to distinguish available oestrogen from that bound to AFP and presumably unavailable to target tissues.

The work was supported by grants CA16831 and ND10071 from the United States Public Health Service. We thank Ms Yvonne Kunz, Mr Rodney Sparks, Dr Hou-chi Dung and Dr Masataka Shiino for assistance. 


\section{References}

Abelev, G.I. (1968) Production of embryonal serum $\alpha$-globulin by hepatomas. Review of experimental and clinical data. Cancer Res. 43, 1344-1350.

Arelev, G.I. (1971) Alpha-fetoprotein in oncogenesis and its association with malignant tumours. $A d v$. Cancer Res. 14, 295-358.

Abflev, G.I. (1974) $\alpha$-Fetoprotein as a marker of embryo-specific differentiations in normal and tumor tissue. Transplant. Rev. 20, 3-37.

Abraham, G.E., Hopper, K., Tulchinsky, D., SWerdioff, R.S. \& Odfll, W.D. (1971) Simultaneous measurement of plasma progesterone, 17 hydroxyprogesterone, and estradiol-17 $\beta$ by radioimmunoassay. Analyt. Letters 4, 325-335.

Adinolfi, A., Adivolfi, M. \& Lessof, M.H. (1975) Alpha-feto-protein during development and in disease. $J$. med. Genetics 12,138-151.

Aussel, C., Urifl. J. \& Mer(ifr-Bodari), C. (1973) Rat alpha-fetoprotein: isolation, characterization and estrogen-binding properties. Biochimie 55, 1431.

CAmeron, I.L. \& PAVlat, W.A. (1976) Stimulation of growth of a transplantable hepatoma in rats by parenteral nutrition.J. natn. Cancer Inst. 56, 597-602.

Davis. B.J. (1964) Disc electrophoresis. II. Method and application to human serum proteins. Anth. N. Y Acad. Sci. 121, 404-427.

Gituln, D. (1975) Normal biology of $\alpha$-fetoprotein. Amn. N. Y. Acad. Sci. 259, 7-16.

La1, P.C.W., Forrester, P.I., Hancolk, R.L., Hay, D.M. \& Lorscheldfr, F.L. (1976) Rat alphafetoprotein: radioimmunoassay and fetal-maternal distribution during pregnancy. $J$. Reprod. Fert. 48. $1-8$.

Ruoslahti, E. \& Рiнko, 11. (1975) Effect of chemical modification on the immunogenicity of homologous $\alpha$-fetoprotein. Ann. N. Y. Acad. Sci. 259. 85-94.

Ruoslahti, E., Pihxo, H. \& Seppala, M. (1974) Alphafetoprotein: immunochemical purification and chemical properties. Expression in normal state and in malignant and non-malignant liver disease. Transplant. Rev. 20, 38-60.

SELL, S. (1973) Alpha-fetoprotein: serum levels in pregnant rats. J. natn. Cancer Inst. 51, 699-701.

SELL, S. (1974) The catabolism of $\alpha_{1}$-fetoprotein and albumin in rats bearing Morris Hepatoma 7777. Cancer Res. 34, 1608-1611.

Sell, S. \& Alexander, D. (1974) Rat alpha-fetoprotein. V. Catabolism and fetal-maternal distribution. $J$. natn. Cancer Inst. 52, 1483-1489.

SELl, S. \& MorRIS, H.P. (1974) Rat $\alpha_{1}$-fetoprotein: relationship to growth rate and chromosome composition of Morris Hepatomas. Cancer Res. 34, 14131417.

Sell, S., Jalowayski, I., Bellone, C. \& Wepsic, H.T. (1972) Isolation and characterization of rat $\alpha_{1-}$ fetoprotein. Cancer Res. 32, 1184-1189.
Sell, S., Nichol.s, M., Becker, F.F. \& Leffert, H.L. (1974a) Hepatocyte proliferation and $\alpha_{1}$-fetoprotein in pregnant, neonatal, and partially hepatectomized rats. Cancer Res. 34, 865-871.

Sel.l, S., Wepsic, H.T., Nickel, R. \& Nichols, M.

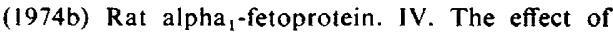
growth and surgical removal of Morris Hepatoma 7777 upon the serum $\alpha_{1} F$ concentration of Buffalo rats. J. natn. Cancer Inst. 52, 133-137.

Sell, S., Becker, F.F., Leffert, H.L. \& Watabe, H. (1976) Expression of an oncodevelopmental gene product ( $\alpha$-fetoprotein) during fetal development and adult oncogenesis. Cancer Res. 36, 4239-4249.

Shijno, M., Williams, G. \& RenNels, E.G. (1972) Ultrastructural observation of pituitary release of prolactin in the rat by suckling stimulus. Endocrinology 90, 176-187.

Siansilawski-Birencwajg, M.,Uriel, J. \& Graber, P. (1967) Association of embryonic antigens with experimentally induced hepatic leșions in the rat. Cancer Res. 27, 1990-1997.

Szentágothai, J., Flerko, B., Mess, B. \& Halasz, B. (1962) Hypothalamic control of the anterior pituitary. An experimental morphological study. Akademiai Kiado, Budapest, pp. 265-288.

Uriel, J., de Nechaud, B. \& Dupiers, M. (1972) Estrogen binding properties of rat, mouse and man fetospecific serum proteins. Demonstration by immunoautoradiographic methods. Biochem. Biophys. Res. Commun. 46, 1175-1180.

Uriel, J., Aussel, C., Bouillon, D., de Nechaud, B. \& LoIstLlier, F. (1973) Localization of rat liver $\alpha$ fetoprotein by cell affinity labelling with oestrogens. Nature, New Biol. 224, 190-192.

Uriel, J., Aussel, C., Boulllon, D., Loisillifr, F. \& DE Nechaud, B. (1975) Liver differentiation and the estrogen-binding properties of $\alpha$-fetoprotein. Ann. N. Y. Acad. Sci. 259, 119-130.

Venable, J.H. \& Coggeshall, R.A. (1965) Simplified lead citrate stain for use in electron microscopy. $J$. Cell Biol. 25, 407-408.

WATABE, H. (1971) Early appearance of embryonic $\alpha$ globulin in rat serum during carcinogenesis with 4dimethylaminoazobenzene. Cancer Res. 31, 11921194.

WATSON, M.L. (1958) Staining of tissue sections for electron microscopy with heavy metals. J. biophys. biochem. Cytol. 4, 475.

Winborn, W.B. \& Seelig, L. (1970) Paraformaldehyde and $\mathrm{s}$-Collidine-A fixative for preserving large blocks of tissue for electron microscopy. Texas Rep. Biol. Med. 28, 347-361. 